\title{
Microencapsulation of Lactobacillus plantarum 299v and its storage in kuini juice
}

\author{
Jian Ting Lai, Ka Wai Lai, Li Yu Zhu, Kar Lin Nyam and Liew Phing Pui* \\ Department of Food Science with Nutrition, Faculty of Applied Sciences, UCSI University, No. 1, Jalan Menara Gading, \\ 56000 Cheras, Kuala Lumpur, Malaysia. \\ Email: puilp@ucsiuniversity.edu.my
}

Received 12 March 2019; Received in revised form 25 November 2019; Accepted 5 March 2020

\begin{abstract}
Aims: Probiotics are living microorganism, when administrated in sufficient quantity can exert beneficial effect to the host. This study focused on the microencapsulation by co-extrusion to increase the viability of Lactobacillus plantarum $299 \mathrm{v}$ (Lp299v) in gastrointestinal conditions, and its storage stability in kuini juice at refrigerated $\left(4^{\circ} \mathrm{C}\right)$ and ambient temperature $\left(25^{\circ} \mathrm{C}\right)$.

Methodology and results: Lp99v was encapsulated with $1.5 \% \mathrm{w} / \mathrm{v}$ sodium alginate and chitosan coating $(0.1 \% \mathrm{w} / \mathrm{v})$ and yielded a microencapsulation efficiency of $97.71 \%$. The Lp299v microbeads produced were spherical in shape and exhibited a mean microbeads size of $618.75 \pm 25.85 \mu \mathrm{m}$. Acid and bile tolerance of both free and encapsulated Lp299v were tested in simulated gastric juice (SGJ) for $2 \mathrm{~h}$ and in simulated intestinal juice (SIJ) for $4 \mathrm{~h}$, respectively. The encapsulated Lp299v maintained above $10^{8} \mathrm{CFU} / \mathrm{mL}$ after exposure to artificial gastrointestinal juice, whereas a significant loss of viability was observed in the free cells. The storage stability of encapsulated Lp299v in kuini juice was determined during 4 weeks of storage at $4{ }^{\circ} \mathrm{C}$ and $25^{\circ} \mathrm{C}$. Results showed that encapsulated Lp299v was capable to remain viable $\left(10^{7} \mathrm{CFU} / \mathrm{mL}\right)$ for at least 4 weeks in a refrigerated condition. However, free Lp299v did not survived under both refrigerated and ambient temperature as the storage period extended.

Conclusion, significance and impact of study: Lp299v entrapped in chitosan-coated alginate microbeads produced by co-extrusion method is able to enhance the viability of Lp299v above the minimum recommended level in harsh environment (gastrointestinal conditions and low $\mathrm{pH}$ of kuini juice).
\end{abstract}

Keywords: Lp299v, microencapsulation, simulated gastrointestinal juices, storage stability

\section{INTRODUCTION}

Recent years have witnessed a growing demand for probiotics products as the public have raised their consciousness on diet-related issue. Probiotics are reported to have extensive beneficial effects to human guts such as reducing constipation, travelers' diarrhea and irritable bowel syndrome (Kechagia et al., 2013). Other health functions include inhibiting the growth of pathogenic bacteria; promoting the synthesis of vitamin B; reducing blood ammonia levels, cholesterol absorption, and tumour formation; and improving calcium absorption (Shi et al., 2013). Hence, based on these advantages related to the probiotics, they have been widely incorporated into many foods and beverages in the modern market (Shah et al., 2016).

In present market, Lactobacillus genera is commonly used for commercial probiotic foods or supplements (Homayouni et al., 2008). Lactobacillus plantarum 299v (Lp299v) is known for its high adhesion rate to the intestinal mucosa (Cremonini et al., 2002). It is able to withstand and grow in harsh environment of the gastrointestinal tracts and is considered as a generally regarded as safe (GRAS) strain. Thus, Lp299v is an edible probiotic which can be applied for food industry (de Vries et al., 2006). Nowadays, this strain has been commercially embodied in many food products such as yogurt and fruit juice (Naruszewicz et al., 2002).

Probiotic products, especially probiotics dairy beverages, have been introduced into the market for many years, are getting more and more popular among lactose non-persistent consumers and vegetarian (Pereiraa et al., 2011; Shah et al., 2016). In recent years, fruit juice has been reported as an ideal medium for probiotics due to its high contents of such as antioxidant, vitamins, minerals and dietary fibers (Nagpal et al., 2012; Perricone et al., 2015; $\mathrm{Ng}$ et al., 2019). In addition, it is exclusive for the growth of probiotics, which means no other starter cultures would compete for the consumption of fruit nutrients (Ding and Shah, 2008).

Mangifera odorata which is also known as kuini, is a mango fruit full of valuable compounds such as polyphenolic components, antioxidants and fibre (Ötles and Ozgoz, 2014; Ariffin et al., 2015). However, factors 
such as extreme $\mathrm{pH}$ environment and storage temperature are the main challenges to maintain the viable cell counts of probiotics in juices (Sheehan et al., 2007). In order to unleash beneficial results to the host, the total amount of live probiotics bacteria should retain at least $10^{7} \mathrm{CFU} / \mathrm{mL}$ throughout the shelf life (Nualkaekul et al., 2013).

Microencapsulation is an effective method to protect probiotics from adverse environments (e.g., gastrointestinal juice and storage condition), and to control the release of probiotics into the end product (Sathyabama et al., 2014; Chew et al., 2019). In addition, microencapsulation techniques are reported to enhance the survivability of probiotics in gastrointestinal ingestion (Brinques and Ayub, 2011; Nazzaro et al., 2012). To date, the co-extrusion microencapsulation of probiotics has yet to be studied extensively.

In view of the above, the first objective of this study was to investigate the efficacy of co-extrusion microencapsulation on the viability of Lp299v after the exposure to simulated gastrointestinal environment. The second objective was to determine the suitability of kuini juice as the ideal vehicle for Lp299v by evaluating the storage stability of free and encapsulated Lp299v in the juice that stored under refrigeration and at room temperature for 4 weeks.

\section{MATERIALS AND METHODS}

\section{Media preparation}

De-Man, Rogosa and Sharpe (MRS) agar (Merck, Germany) was prepared by dissolving $68.20 \mathrm{~g}$ of MRS agar powder in $1 \mathrm{~L}$ of distilled water. The powder was dissolved well and autoclaved (HV-110, Hirayama, Japan) for 15 mins at $121^{\circ} \mathrm{C}$. After autoclaving, molten agar was cooled off in water bath set at $55^{\circ} \mathrm{C}$. After that, a layer of MRS agar was poured on the surface of Petri dishes inside a sterilized laminar flow station. The plates were then left open to avoid the formation of water vapor on the surface of lids. Once the agar became solid, all the plates were stacked up on top of the other and sealed properly with parafilm.

MRS broth (Merck, Germany) was made by dissolving $5.22 \mathrm{~g}$ of MRS broth powder in $100 \mathrm{~mL}$ of distilled water. The mixture was mixed well to ensure the dissolution of the powder, followed by autoclaving at $121^{\circ} \mathrm{C}$ for $15 \mathrm{~min}$. After autoclaving, MRS broth was cooled down to room temperature before the addition of probiotic L. plantarum 299v (Lp299v).

Phosphate buffer saline (PBS) is a balanced salt solution containing $0.20 \mathrm{~g} / \mathrm{L}$ of $\mathrm{KCl}$ (J-Kollin, UK), $1.44 \mathrm{~g} / \mathrm{L}$ of $\mathrm{Na}_{2} \mathrm{HPO}_{4}$ (Merck, Germany), $0.24 \mathrm{~g} / \mathrm{L}$ of $\mathrm{KH}_{2} \mathrm{PO}_{4}$ (Merck, Germany) and $8.00 \mathrm{~g} / \mathrm{L}$ of $\mathrm{NaCl}$ (R\&M Chemicals, UK) (Zneimer et al., 2017). The mixture was regulated to $\mathrm{pH} 7.4$ with $1 \mathrm{M} \mathrm{HCl}$ (Merck, Germany) or $1 \mathrm{M} \mathrm{NaOH}$ (Merck, Germany) by a calibrated $\mathrm{pH}$ meter and autoclaved. The autoclaved PBS was used for washing cells after centrifugation and microencapsulation process.
Preparation of simulated gastrointestinal juices (SGJ) and simulated intestinal juice (SIJ)

Simulated gastric juice (SGJ) was prepared according to Chia et al. (2015) with slight adjustment. SGJ was prepared by mixing $9.0 \mathrm{~g}$ of $\mathrm{NaCl}$ and $3.0 \mathrm{~g}$ of pepsin in 1 $\mathrm{L}$ of distilled water. The SGJ was adjusted to $\mathrm{pH} 2.0$ with $\mathrm{HCl}$ using a calibrated $\mathrm{pH}$ meter.

Simulated intestinal juice (SIJ) was prepared as described by Chia et al. (2015) with slight adjustment. SIJ was prepared by dissolving $3.4 \mathrm{~g}$ of $\mathrm{KH}_{2} \mathrm{PO}_{4}$ in $95 \mathrm{~mL}$ of $\mathrm{NaOH}$ solution and then topped up to $500 \mathrm{~mL}$ with distilled water. After that, $10.0 \mathrm{~g}$ of bile salt was added subsequently, and $\mathrm{pH}$ was adjusted to 7.2.

\section{Preparation of probiotics}

The preparation of Lp299v culture (BiO-LiFE, Malaysia) was adapted from Albadran et al. (2015) with modifications. Lp299v was cultivated in $100 \mathrm{~mL}$ of autoclaved MRS broth and incubated at $37^{\circ} \mathrm{C}$ for $24 \mathrm{~h}$. The cells were then collected by centrifugation (Allegera ${ }^{\mathrm{TM}} \mathrm{X}-22 \mathrm{R}$, Beckman Coulter Life Sciences, USA) for $15 \mathrm{~min}$ with $3200 \mathrm{rpm}$ at $4{ }^{\circ} \mathrm{C}$. After centrifugation, the supernatant was discarded, and the pellets were washed twice with PBS. The pellets were then re-suspended in $100 \mathrm{~mL}$ PBS. Lp299v was mixed thoroughly by vortex mixer (VTX-3000 L, LMS, Japan) for $30 \mathrm{~s}$ and then was used for microencapsulation.

\section{Cell enumeration}

The dissolution of encapsulated Lp299v cells was carried out according to Tootoonchi et al. (2015) with modification prior to the cell enumeration. The first dilution was prepared by adding $1 \mathrm{~g}$ of chitosan-coated alginate microbeads in $9 \mathrm{~mL}$ of trisodium citrate solution (Bendosen, Germany). The sample was then sent to stomacher machine (BagMixer® $400 \mathrm{~W}$ ) for $2 \mathrm{~min}$ at normal speed to ensure the capsules were fully decomposed. After the decomposition of the microbeads, cells enumeration was carried out according to Shinde et al. (2013) with adaptations to determine the viability of Lp299v. Sequential dilution was conducted by serially diluting $1 \mathrm{~mL}$ of the mixture with $9 \mathrm{~mL}$ of peptone (Merck, Germany) water $(0.1 \% \mathrm{w} / \mathrm{v})$ until $10-8$ fold dilution.

After the completion of serial dilution, the samples of each dilution were mixed well by using vortex mixer before adding $0.1 \mathrm{~mL}$ of aliquot onto the MRS agar Petri dishes. The Petri dishes were placed in incubator at $37^{\circ} \mathrm{C}$ for $48 \mathrm{~h}$. After $48 \mathrm{~h}$ of incubation, the amount of colonies on the MRS agar plates were counted. The viable cell counts of bacteria in the initial sample was calculated as formula below (Siang et al., 2019).

Viable cell count $\left(\log _{10} \mathrm{CFU} / \mathrm{mL}\right)=\log$ [Average number of colonies from triplicate plates/ (Dilution factor $\times$ volume plated)] 
The survivability for both encapsulated and nonencapsulated Lp299v was calculated as formula below:

Survivability $(\%)=\left[\left(\log N / \log N_{0}\right)\right] \times 100 \%$

where $\log N$ indicates the number of viable cell count $(\mathrm{CFU} / \mathrm{mL})$ at a specific time and $\log \mathrm{N}_{0}$ indicates the initial viable cell count $(\mathrm{CFU} / \mathrm{mL})$ at the beginning (Savedboworn et al., 2017).

\section{Microencapsulation of Lp299v by using co-extrusion technique}

Microencapsulation of Lp299v was carried out using coextrusion method. The shell solution $(1.5 \% \mathrm{w} / \mathrm{v})$ sodium alginate was prepared by dissolving $6.0 \mathrm{~g}$ of sodium alginate powder (R\&M Chemicals, UK) in $394 \mathrm{~mL}$ ultrapure water. The solution was then homogenized by using T25 digital Ultra-Trax homogenizer (IKA, Malaysia) at $12000 \mathrm{rpm}$ for $2 \mathrm{~min}$. The homogenized solution was pasteurized using double boiler technique at $85^{\circ} \mathrm{C}$ for 30 min (Shinde et al., 2013). The sterile sodium alginate solution was then stored in a sterilized Schott bottle at 4 ${ }^{\circ} \mathrm{C}$ overnight for further usage (Tootoonchi et al., 2015).

The preparation of chitosan solution $(0.1 \% \mathrm{w} / \mathrm{v})$ was according to Ahonkhai et al. (2006) with minor modification that $1 \mathrm{~g}$ of chitosan powder (R\&M Chemicals, UK) was dissolved in $900 \mathrm{~mL}$ ultra-pure water which had been acidified with $10 \mathrm{~mL}$ glacial acetic acid (Friendemann Schmidt, Australia). After that, $30 \mathrm{~g}$ of $\mathrm{CaCl}_{2}$ (R\&M Chemicals, UK) and $1 \mathrm{~g}$ of Tween 80 (R\&M Chemicals, UK) were dissolved in the chitosan solution, then the $\mathrm{pH}$ of the solution was adjusted to 5 with $\mathrm{NaOH}$ (Nazzaro et al., 2012). The chitosan solution was pasteurized at $72{ }^{\circ} \mathrm{C}$ for $30 \mathrm{sec}$ and then cooled down into room temperature prior microencapsulation.

Encapsulation of Lp299v was conducted by using the Büchi Encapsulater B-390 equipped with inner and outer nozzle. During encapsulation, the core substance (Lp299v) and the shell material (sodium alginate solution) were pumped through the outer $(300 \mu \mathrm{m})$ and inner $(150$ $\mu \mathrm{m})$ nozzles simultaneously by the $600 \mathrm{mbar}$ air pressure to form a core-shell fluid stream. The microbeads were sprayed out through the nozzle under a vibration frequency of $300 \mathrm{~Hz}$, and at the same time a $1.5 \mathrm{kV}$ voltage was used (Chew et al., 2015).

The microbeads produced became firm after immersing in sterile chitosan solution for $30 \mathrm{~min}$. The microbeads were then collected through a sieve and rinsed thoroughly with sterilized PBS. Subsequently the microcapsules were dried by tissue papers before transferring to bottle wrapped with aluminum foil and stored at $4^{\circ} \mathrm{C}$.

\section{Encapsulation yield}

The mean diameter of the microbeads was measured by using optical microscope (CX31, Olympus, Japan) and stage micrometer. The encapsulation yield was a comprehensive evaluation of entrapment efficiency and cell survivability during the microencapsulation process (Zanjani et al., 2014). Encapsulation yield was calculated as follows:

Encapsulation yield $(\%)=[($ Number of viable cells released from microbeads/ number of viable cell in bacterial culture) $] \times 100 \%$

\section{Acid tolerance test}

The acid tolerance test was designed according to Pimentel-González et al. (2009) with slight adjustments. To examine the survivability of encapsulated Lp299v under simulated gastric condition, $1 \mathrm{~g}$ of microbeads and $1 \mathrm{~mL}$ of free cells were separately added into $9 \mathrm{~mL}$ of sterilized SGJ for 0,1 and $2 \mathrm{~h}$ at $37{ }^{\circ} \mathrm{C}$. After each interval, the microbeads and free cells were rinsed twice with PBS and centrifuged (3200 rpm for $15 \mathrm{~min}$ at $4^{\circ} \mathrm{C}$ ) to remove the excess SGJ. The supernatant was discarded, and the microbeads was suspended in $9 \mathrm{~mL}$ of trisodium citrate solution for dissolution. The microbeads were solubilized completely in a stomacher machine for 2 min to release the probiotic cells. The solution was then serially diluted by using peptone water $(0.1 \% \mathrm{w} / \mathrm{v})$. Aliquots $(0.1 \mathrm{~mL})$ was plated onto MRS agar plates and the viability for free cells and the microbeads were represented as colony forming unit per milliliter $(\mathrm{CFU} / \mathrm{mL})$.

\section{Bile tolerance test}

Bile tolerance test was adapted from Su et al. (2011) with modification. In order to evaluate the survival of free and encapsulated Lp299v in the presence of bile salts, $1 \mathrm{~g}$ of the microbeads or $1 \mathrm{~mL}$ of free cells which had been incubated in SGJ after $2 \mathrm{~h}$ were suspended in $9 \mathrm{~mL}$ of sterile SIJ. The viable cell counts were then tested at time interval of every $0,1,2,3$ and $4 \mathrm{~h}$ at $37^{\circ} \mathrm{C}$. Both microbeads and free cells were rinsed twice with PBS and centrifuged ( $3200 \mathrm{rpm}$ for $15 \mathrm{~min}$ at $4^{\circ} \mathrm{C}$ ) to remove the excess SIJ. The microbeads was suspended in $9 \mathrm{~mL}$ of trisodium citrate solution for dissolution. The microbeads were dissolved completely in stomacher machine for 2 min to release the probiotic cells from the microbeads. After that, each suspension was serially diluted in peptone water $(0.1 \% \mathrm{w} / \mathrm{v})$. Then, $0.1 \mathrm{~mL}$ of samples from each time interval were inoculated on MRS agar plates and incubated at $37^{\circ} \mathrm{C}$ for $48 \mathrm{~h}$ to determine the viability.

\section{Cells survival during storage in kuini juice}

The determination of viability for both free and encapsulated Lp299v cells during storage in kuini fruit juice was adapted from Teanpaisan et al. (2015) with modification. Well matured kuini fruit was washed with tap water, and then it was peeled and well blended by a juicer. The fibrous pulp of the fruit juice was filtered via a sieve. After went through pasteurization at $80^{\circ} \mathrm{C}$, it was stored at $4{ }^{\circ} \mathrm{C}$ for further usage.

To evaluate the viability of encapsulated Lp299v in kuini juice under different storage temperatures, $10 \mathrm{~mL}$ of 
free cell or $10 \mathrm{~g}$ of encapsulated Lp299v were added into $100 \mathrm{~mL}$ of pasteurized kuini juice separately. The juice was stored for 4 weeks at $4{ }^{\circ} \mathrm{C}$ and $25^{\circ} \mathrm{C}$. The cultivation of probiotics was conducted by incubating at $37^{\circ} \mathrm{C}$ for 48 $\mathrm{h}$, and the enumeration of the probiotic cells was carried out on a weekly basis over a period of 4 weeks using colony counting on MRS agar.

\section{Statistical analysis}

All tests were conducted in triplicates. The results were expressed as average mean \pm standard deviation. One way analysis of variance (ANOVA) and paired T-test were analyzed by using IBM SPSS Statistics 22 . The average values were compared with Tukey's post hoc test for one way ANOVA. The differences were considered significantly at the level of $p<0.05$.

\section{RESULTS AND DISCUSSION}

\section{Encapsulation yield}

In this study, L. plantarum 299v (Lp299v) was entrapped with sodium alginate through co-extrusion method and coated with chitosan. The mean microbeads size, encapsulation efficiency and the physical properties of the microbeads were evaluated after the production of microbeads. Figure 1 shows that the morphology of Lp299v microbead were spherical in shape with smooth round surface. Table 1 shows that the mean Lp299v microbeads size was $618.75 \pm 25.85 \mu \mathrm{m}$. Similar microbeads size range $(530-624 \mu \mathrm{m})$ was also reported by Yee et al. (2019) in the locust bean gum coatedalginate microbeads entrapping Lactobacillus acidophilus NCFM which produced by co-extrusion.

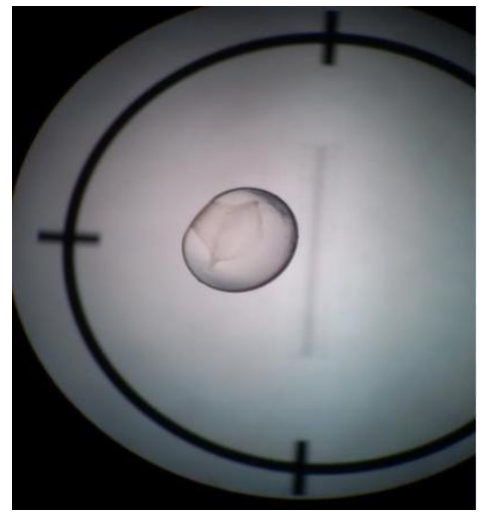

Figure 1: The morphology of Lp299v microbead under microscope.

Encapsulation yield refers to the efficiency of the probiotic entrapment and survival rates of viable cells after microencapsulation process. It is crucial to ensure co-extrusion is applicable and efficient to protect Lp299v from stress condition. The encapsulation yield of Lp299v was $97.71 \pm 0.18 \%$. The viable cell counts of Lp299v in the bacterial culture (before encapsulation) was 11.15$11.31 \log _{10} \mathrm{CFU} / \mathrm{mL}$ while, a high entrapment efficiency was obtained after encapsulation, with a viability of $10.93-$ $11.01 \log _{10} \mathrm{CFU} / \mathrm{mL}$. The results indicated that no considerable viability loss of Lp299v was observed after the co-extrusion encapsulation process.

Table 1: Mean microbeads size and encapsulation yield (\%) of Lp299v.

\begin{tabular}{|c|c|c|c|}
\hline $\begin{array}{l}\text { Mean of } \\
\text { microbeads } \\
\text { size } \\
(\mu \mathrm{m})\end{array}$ & $\begin{array}{l}\text { Viable } \\
\text { cell count } \\
\text { in the } \\
\text { bacteria } \\
\text { culture } \\
\text { (log } \\
\text { CFU/mL) }\end{array}$ & $\begin{array}{l}\text { Viable cell } \\
\text { count } \\
\text { released } \\
\text { from the } \\
\text { microbeads } \\
\text { (log } \\
\text { CFU/mL) }\end{array}$ & $\begin{array}{l}\text { Encapsulat } \\
\text { ion yield } \\
(\%)\end{array}$ \\
\hline $\begin{array}{l}618.75 \pm \\
25.85\end{array}$ & $\begin{array}{l}11.23 \pm \\
0.08\end{array}$ & $\begin{array}{l}10.97 \pm \\
0.04\end{array}$ & $\begin{array}{l}97.71 \pm \\
0.18\end{array}$ \\
\hline
\end{tabular}

In this study, an encapsulation yields above $97 \%$ was obtained via microencapsulation method. The results were in agreement with de Prisco et al. (2015) who have reported that Lactobacillus reuteri DSM 17938 entrapped in chitosan-alginate matrix was able to achieve high encapsulation yield (97\%). In addition, Haghshenas et al. (2015) also reported that a high encapsulation yield (> $98 \%$ ) was obtained though microencapsulation of probiotic bacteria $L$. plantarum $15 \mathrm{HN}$ by using alginate as wall material.

The entire co-extrusion process did not include any harmful factors such as high heat treatment or high shear stress, therefore resulted in a high encapsulation efficiency (Nag, 2011; Siang et al., 2019). Besides that, the careful selection of wall materials and the prudent operations throughout the whole microencapsulation process also led to a high entrapment efficiency (Mortazavian et al., 2007). The formation of polyelectrolyte complex between the amino groups (chitosan) and the carboxyl groups (alginate) which stabilizes the entrapped active ingredient and enhanced the encapsulation efficiency (Chew et al., 2015).

Survival of free and encapsulated Lp299v in simulated gastric juice (SGJ)

Stomach acid creates an acidic environment in digestive tract which inhibit the proliferation of most of the microbes, hence, acid tolerance is a critical prerequisite for the selection of probiotic strains (Song et al., 2015). The acid tolerant ability of free and encapsulated Lp299v were evaluated by determining their viability after $2 \mathrm{~h}$ incubations in SGJ which was presented in Figure 2. The initial viable cell counts of free and encapsulated Lp299v was 9.39 and $9.28 \log _{10} \mathrm{CFU} / \mathrm{mL}$, respectively. The viability of free and encapsulated Lp299v decreased throughout the incubation in SGJ. Free Lp299v exhibited higher cell reduction ( 0.65 log reduction) as compared to the encapsulated Lp299v (0.33 log reduction) (Figure 2). 
At the end of SGJ incubation, encapsulated Lp299v was 1.02-fold higher than the free Lp299v. This is due to the protection from the chitosan coated-alginate microbeads against low pH of gastric acids (Mustafa et al., 2016).

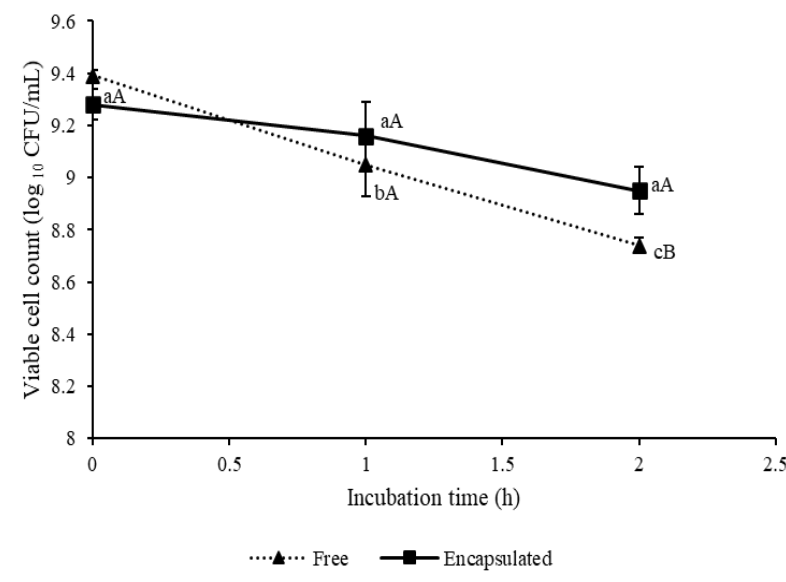

Figure 2: Total viable counts of free and encapsulated Lp299v in SGJ at pH 2.0 for 2 h. Error bars are represented as \pm standard deviation of three replicates $(n=3)$. The letters a-c indicate the significant difference $(p$ $<0.05)$ of Lp299v at different incubation time. The letters A-B indicate the significant difference $(p<0.05)$ of different forms of Lp299v on the same incubation time.

Although both free and encapsulated Lp299v showed a decrease in viability after $2 \mathrm{~h}$ of SGJ incubation, the number of viable Lp299v were above the minimum recommendation of $10^{7} \mathrm{CFU} / \mathrm{mL}$ (Sabnis and Malavkar, 2016). The results also indicated that encapsulated Lp299v has a stronger ability to tolerate towards acidic environment as compared to free cells. The result was in agreement with Shi et al. (2013) such that the viable cell counts of encapsulated Lactobacillus bulgaricus is able to maintain at least $8.00 \log _{10} \mathrm{CFU} / \mathrm{mL}$ after $2 \mathrm{~h}$ incubation in SGJ at pH 2. Nualkaekul et al. (2012) reported that chitosan coating can improve the survivability of $L$. plantarum up to an amount of $0.50-1.00 \log _{10} \mathrm{CFU} / \mathrm{mL}$ at the end of gastric digestion.

Encapsulated Lp299v showed a high survivability (approximately 96\%) after $2 \mathrm{~h}$ incubation in SGJ (Figure 2). The results demonstrated that co-extrusion microencapsulation method had significantly improved probiotics viability in acidic gastric condition at $\mathrm{pH} 2$. Similar trend of results was observed by Sathyabama et al. (2014) that the encapsulated probiotics showed high survivability (88.75-98.75\%) after simulated gastric digestion at $\mathrm{pH} 2$ to 3 for $24 \mathrm{~h}$.

The higher survival rate of encapsulated Lp299v can be attributed to the effective protection provided by the wall material (Mustafa et al., 2016). The buffering nature of polysaccharides enhanced the protection against gastric medium, therefore avoided Lp299v from directly contacting with gastric acid. The electrostatic interaction had generated a strong binding between chitosan and alginate, therefore improved the probiotics survivability remarkably (Etchepare et al., 2015)

\section{Survival of free and encapsulated Lp99v in simulated intestinal juice (SIJ)}

After passing the stomach and right before reaching the colon, probiotics need to pass through an organ called small intestine. The small intestine contains high concentration of bile salts which are not bacteria-friendly and can inhibit the growth of bacteria (Cook et al., 2012). To be considered as a good probiotics strain, the bacteria needs to not only withstand extreme environment such as low $\mathrm{pH}$ and high bile salts concentration, but also confer health effects to the host. Hence, bile tolerance is a vital criterion in selecting probiotics strain (Hamon et al., 2011). In this study, the bile salt tolerance capacity of free and encapsulated Lp99v was evaluated to determine their viability during SIJ digestion. Free and encapsulated Lp99v were subjected to SGJ digestion for $2 \mathrm{~h}$, followed by a further incubation in SIJ with $2 \% \mathrm{w} / \mathrm{v}$ bile salt for 0,1 , 2,3 , and $4 \mathrm{~h}$. The results are depicted in Figure 3.

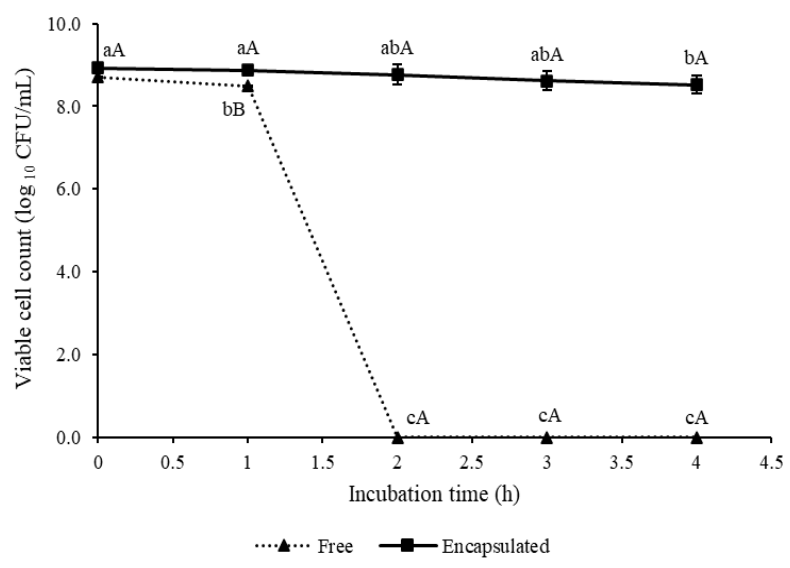

Figure 3: Total viable counts of free and encapsulated Lp299v in SIJ incubated at $\mathrm{pH} 7.2$ for $4 \mathrm{~h}$. Error bars are represented as \pm standard deviation of three replicates $(n=3)$. The letters a-c indicate the significant difference $(p$ $<0.05)$ of Lp299v at different incubation time. The letters A-B indicate the significant difference $(p<0.05)$ of different forms of Lp299v on the same incubation time.

Probiotic bacteria must able to survive in intestinal juice with relatively high concentration of bile salts (Sahadeva et al., 2011). Figure 3 shows that the viability of free and encapsulated Lp299v decreases throughout the SIJ digestion with least pronounced in encapsulated Lp299v. Free Lp299v did not survived after $2 \mathrm{~h}$ of incubation in SIJ while encapsulated Lp299v experienced a $0.41 \mathrm{log}$ reduction at the end of SIJ digestion (Figure 3 ). This indicated that free Lp299v is vulnerable to bile salts as the toxic effect of bile salts can destroy the microbial membrane (Solheim et al., 2007). The results were in agreement with Chávarri et al. (2010) who reported that 
the number of Lactobacillus gasseri survived after $60 \mathrm{~min}$ of incubation (SIJ with $3 \% \mathrm{w} / \mathrm{v}$ bile salt) was $4.48 \log _{10}$ $\mathrm{CFU} / \mathrm{mL}$ and the viability was dropped to less than 1 $\log _{10} \mathrm{CFU} / \mathrm{mL}$ after $120 \mathrm{~min}$.

Controversially, the viability of encapsulated Lp299v (8.52 $\log _{10} \mathrm{CFU} / \mathrm{mL}$ ) was greater than the minimum recommended dosage of $10^{7} \mathrm{CFU} / \mathrm{mL}$ during prolonged digestion in SIJ. Annan et al. (2008) reported that the viability of encapsulated Bifidobacterium adolescentis was more than $7 \log _{10} \mathrm{CFU} / \mathrm{g}$ after $3 \mathrm{~h}$ incubation in SIJ at $\mathrm{pH}$ 7.4.

Encapsulated Lp299v showed a better survival ( 0.16 log reduction in cell viability, Figure 3 ) as compared to $L$. bulgaricus (2.10 log reduction in cell viability) after $2 \mathrm{~h}$ exposure in $2 \% \mathrm{w} / \mathrm{v}$ bile salt solution (Shi et al., 2013). In addition, Hansen et al. (2002) also found that viability of encapsulated $B$. adolescentis dropped by about $2 \log _{10}$ $\mathrm{CFU} / \mathrm{mL}$ after $2 \mathrm{~h}$ of incubation in $0.5 \% \mathrm{w} / \mathrm{v}$ bile at $37^{\circ} \mathrm{C}$. This is due to the coating of chitosan provided probiotics a better protection in SIJ. However, Siang et al. (2019) reported that Lactobacillus rhamnosus GG entrapped in poly-L-lysine coated-alginate microbeads was unable to preserve the probiotic viability throughout the SIJ incubation.

In the simulated sequential digestive process of SG $(2 \mathrm{~h})$ and SIJ (4 h), higher numbers of Lp299v survived in the chitosan-alginate microbeads $\left(10^{8} \mathrm{CFU} / \mathrm{mL}\right)$ than the free Lp299v. Moreover, a strong bile tolerance was observed in encapsulated Lp299v with a high survivability $(95.41 \%)$ after $4 \mathrm{~h}$ of incubation in SIJ (Figure 3). de Prisco et al. (2015) also declared that microencapsulation by chitosan-alginate matrix could improve tolerance of $L$. reuteri towards SIJ due to the formation of insoluble complex between chitosan and the bile salt. Therefore, the penetration of bile salt into the microcapsule can be mitigated, and the shell material can protect probiotics cells from exposing to toxic environment (Sabnis and Malavkar, 2016).

\section{Survival of free and encapsulated Lp299v in kuini juice during 4 weeks of storage}

Maintaining the viability and the activity of probiotics in fruit juice to the end of product shelf life are the two important criterions need to be fulfilled for probiotics fruit juices (Perricone et al., 2015). However, it is challenging in food product because of the intrinsic factors of food matrices, processing methods, and different storage conditions (low pH environment and storage temperature) (Ozcan et al., 2015). It is crucial to test the effectiveness of encapsulated Lp299v produced by co-extrusion in protecting the probiotics from the adverse environment including acidic environment in kuini juice and storage temperature.

In this study, both forms of Lp299v (free and encapsulated) were added into kuini juice ( $\mathrm{pH} 3.5-3.6)$ and their storage stability were evaluated during 4 weeks of storage at $25^{\circ} \mathrm{C}$ and $4{ }^{\circ} \mathrm{C}$. The viabilities of free and encapsulated Lp299v that stored at $25{ }^{\circ} \mathrm{C}$ and $4{ }^{\circ} \mathrm{C}$ are presented in Figures 4 and 5, respectively.
Figure 4 shows that the viability of free and encapsulated Lp299v decreases throughout the storage after incorporation into kuini juice that stored at $25^{\circ} \mathrm{C}$. Free Lp299v experienced 1.18-2.11 log reduction in cell viability during the first 3 weeks of storage at room temperature. On the other hand, the loss of viability was less pronounced in encapsulated Lp299v. The encapsulated Lp299v shows higher in viability (by $25.54 \%$ ) as compared to free Lp299v during 3 weeks of storage in kuini juice at $25{ }^{\circ} \mathrm{C}$ (Figure 4). This suggested that the Lp299v entrapped in chitosan-alginate matrix produced by co-extrusion was able to preserve the cell viability in adverse conditions (low $\mathrm{pH}$ and high storage temperature) (de Prisco et al., 2015). This was due to the structure of microbeads that acts as a physical barrier separating probiotics from the acidic environment of fruit juices (Nualkaekul et al., 2012; Perricone et al., 2015).

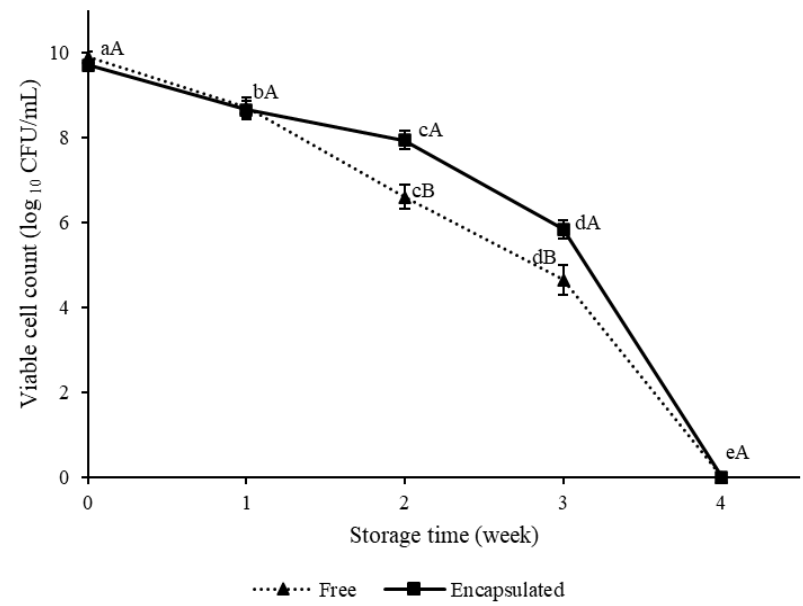

Figure 4: Total viable counts of free and encapsulated Lp299v in kuini juice during 4 weeks of storage at $25^{\circ} \mathrm{C}$. Error bars are represented as \pm standard deviation of three replicates $(n=3)$. The letters a-e indicate the significant difference $(p<0.05)$ of Lp299v at different incubation time. The letters $A-B$ indicate the significant difference $(p<0.05)$ of different forms of Lp299v on the same incubation time.

However, at $4^{\text {th }}$ week of storage, the viable cell counts of free and encapsulated Lp299v declined to $0 \log _{10}$ $\mathrm{CFU} / \mathrm{mL}$. This was probably due to low $\mathrm{pH}$ and the polyphenolic content of kuini juice that has antimicrobial effect (Adnan et al., 2018: Nualkaekul et al., 2013; Perricone et al., 2015). The low pH of the kuini juice is due to the presence of organic acids such as malic, tartaric and critic acids (Imran et al., 2017). Since free Lp299v were expose directly to the organic acids and polyphenolic compounds, therefore, viability is lower as compared to encapsulated Lp299v. Phoem et al. (2015) also reported that the viability of free Bifidobacterium longum was significantly lower than the co-encapsulated form (alginate-Eleutherine americana extract) after 15 days of storage in pineapple juice. 
The encapsulated Lp299v was only able to preserve the cell viability (above $10^{7} \mathrm{CFU} / \mathrm{mL}$ ) within 2 weeks of room temperature storage in kuini juice. This is possibly due to the diffusion of acids or polyphenolic compounds into the microbeads that are detrimental to the entrapped Lp299v (Moghtader et al., 2017). In addition, the diffusion rate was higher at room temperature (Hess et al., 2014). Therefore, drastic reduction in viability of encapsulated Lp299v was observed after 4 weeks of storage in kuini juice. Similar trend was observed when the free $L$. acidophilus NCFM was did not survived after two weeks of storage in mulberry leaf tea at $25{ }^{\circ} \mathrm{C}$ while the encapsulated form can survive after 4 weeks of storage (Yee et al., 2019).

The results of this study were in agreement with $\mathrm{Ng}$ et al. (2019) who reported that the maintenance of the viability of probiotics above the minimum recommended concentration could be challenging especially when it is under room temperature. This is because the metabolic activity was higher at $25{ }^{\circ} \mathrm{C}$ as compared refrigeration temperature (Matejčeková et al., 2019). The viability of free Lp299v decline possibly due to the accumulation of toxic substances as a results of cell division during extended storage in fruit juice (Chaudhary, 2019). However, co-extrusion encapsulation of the Lp299v by using alginate-chitosan matrix was able to improve its viability to a large extent when the encapsulated Lp299v was incorporated in kuini juice that stored at refrigerated temperature (Figure 5).

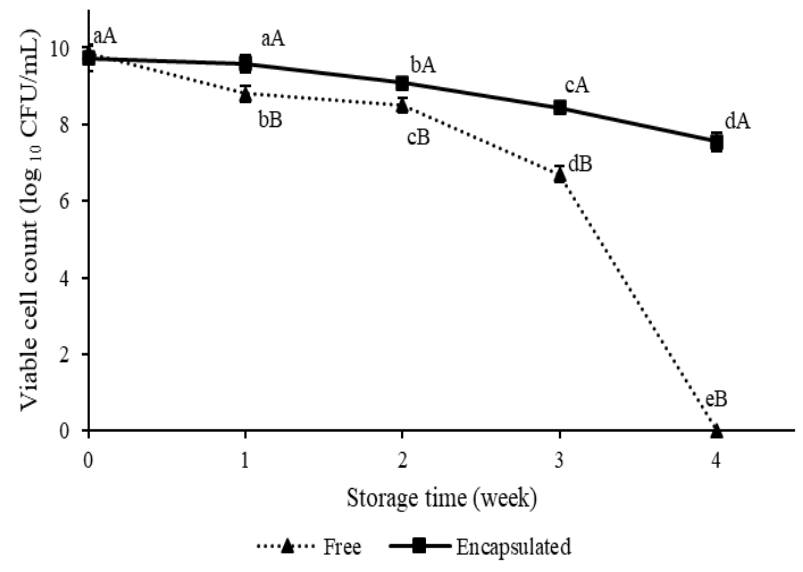

Figure 5: Total viable counts of free and encapsulated Lp299v in kuini juice during 4 weeks of storage at $4{ }^{\circ} \mathrm{C}$. Error bars are represented as \pm standard deviation of three replicates $(n=3)$. The letters a-e indicate the significant difference $(p<0.05)$ of Lp299v at different incubation time. The letters $A-B$ indicate the significant difference $(p<0.05)$ of different forms of Lp299v on the same incubation time.

Figure 5 shows the viable cell counts of both free and encapsulated Lp299v at storage condition of $4{ }^{\circ} \mathrm{C}$ in kuini juice. A declining trend was observed in terms of the viability of Lp299v over the storage time with more pronounced in the free Lp299v. The viability of counts of free Lp299v showed a gradual declination from $9.86 \log _{10}$ $\mathrm{CFU} / \mathrm{mL}$ at week 0 to $8.51 \log _{10} \mathrm{CFU} / \mathrm{mL}$ at week 2 . The viability of Lp299v experienced 1.82 log reduction at week 3 of refrigeration and did not survived at the end of storage in kuini juice (Figure 5).

This was in agreement with Nualkaekul et al. (2012) who studied the storage stability of $L$. plantarum NCIMB 8826 and $B$. longum NCIMB 8809 in pomegranate juice and both probiotic strains died after 4 weeks of storage at $4{ }^{\circ} \mathrm{C}$. The drastic fall in the viability of free Lp299v in kuini juice was most likely associated with the low $\mathrm{pH}$ and the polyphenolic contents of the kuini juice (Nualkaekul et al., 2013; Perricone et al., 2015). On the other hand, a steady decreasing trend with a total of 2.18 log reduction in the viabilities was observed after 4 weeks of storage in kuini juice at $4{ }^{\circ} \mathrm{C}$. The viable count of encapsulated Lp299v decreased slowly from $9.72 \log _{10} \mathrm{CFU} / \mathrm{mL}$ at week 0 to $7.54 \log _{10} \mathrm{CFU} / \mathrm{mL}$ at week 4 (Figure 5 ), while the viability dropped to $0 \log _{10} \mathrm{CFU} / \mathrm{mL}$ at room temperature (Figure 4). This suggests that the viability of Lp299v in fruit juice is affected by the storage temperature, and a lower storage temperature has a higher stability on the entrapped probiotics (Perricone et al., 2015).

Ding and Shah (2008) reported that the encapsulated probiotics in orange juice and apple juice had a higher survivability than their respective free cells after 6 weeks of storage at $4{ }^{\circ} \mathrm{C}$. Moreover, Teanpaisan et al. (2015) also reported that the viability of microencapsulated Lactobacillus paracasei SD1 was significantly higher than that of free cells in orange and aloe vera juices during 8 weeks of storage under refrigeration.

After 4 weeks of storage in kuini juice, only the encapsulated Lp299v stored at $4{ }^{\circ} \mathrm{C}$ exhibited viability higher than the minimum level $\left(7 \log _{10} \mathrm{CFU} / \mathrm{mL}\right)$ to confer the health benefits to the host (Mansouripour et al., 2013). Bruno and Shah (2003) revealed that the best method to protect the viability of probiotics in capsulated supplements is to store them in a cool temperature instead of room temperature. It is in accordance to our findings, in which the greater loss of free and encapsulated Lp299v was observed in room temperature instead of at $4{ }^{\circ} \mathrm{C}$. The obtained results show that coextrusion encapsulation as an emerging technology is able to improve viability of Lp299v (entrapped in chitosan coated-alginate microbeads) during gastrointestinal conditions and its storage stability in kuini juice under refrigeration.

\section{CONCLUSION}

The Lp299v entrapped in chitosan coated-alginate microbeads produced by co-extrusion were spherical in shape with a mean size of $618.75 \pm 25.85 \mu \mathrm{m}$ and high encapsulation yield $(97.71 \%)$. The encapsulated Lp299v was able to preserve the its viability in the adverse environment such as during sequential simulated gastrointestinal digestion and refrigerated storage in kuini juice for 4 weeks with viability above the minimum recommended level $\left(10^{7} \mathrm{CFU} / \mathrm{mL}\right)$. However, the free 
Lp299v did not survive after $2 \mathrm{~h}$ of incubation in SIJ and at the end of storage in kuini juice at refrigerated and room temperature. This is due to the protective effect of the chitosan coating on the alginate microbeads that protect the entrapped Lp299v against low pH environment (during gastric digestion and fruit juice) and the presence of bile. This study shows that kuini juice is an ideal medium for the delivery of encapsulated Lp299v. The kuini juice containing encapsulated Lp299v is suitable for vegans and consumers with lactose intolerance.

\section{ACKNOWLEDGEMENTS}

The project was supported by UCSI University Pioneer Scientist Incentive Fund (PSIF) grant (Proj-In-Fas-055).

\section{REFERENCES}

Adnan, H., Ali, M. S. M., Hassan, H., Manan, M. A., Ghazali, M. N. and Ramli, N. S. N. (2018). Bioassayguided of fresh and fermented kuini (Mangifera odorata) extracts against bacteria activity. International Journal of Agriculture, Forestry00099 and Plantation 7, 27-32.

Ahonkhai, E., Arhewoh, I. and Okhamafe, A. (2006). Effect of solvent type and drying method on protein retention in chitosan-alginate microcapsules. Tropical Journal of Pharmaceutical Research 5(2), 583-588.

Albadran, H., Chatzifragkou, A., Khutoryanskiy, V. and Charalampopoulos, D. (2015). Stability of probiotic Lactobacillus plantarum in dry microcapsules under accelerated storage conditions. Food Research International 74, 208-216.

Annan, N., Borza, A. and Hansen, L. (2008). Encapsulation in alginate-coated gelatin microspheres improves survival of the probiotic Bifidobacterium adolescentis 15703T during exposure to simulated gastro-intestinal conditions. Food Research International 41(2), 184-193.

Ariffin, Z., Md-Sah, M., Idris, S. and Hashim, N. (2015). Genetic diversity of selected mangifera species revealed by inter simple sequence repeats markers. International Journal of Biodiversity 2015, Article ID 458237.

Brinques, G. and Ayub, M. (2011). Effect of microencapsulation on survival of Lactobacillus plantarum in simulated gastrointestinal conditions, refrigeration, and yogurt. Journal of Food Engineering 103(2), 123-128.

Bruno, F. and Shah, N. (2003). Viability of two freezedried strains of Bifidobacterium and of commercial preparations at various temperatures during prolonged storage. Journal of Food Science 68(7), 2336-2339.

Chávarri, M., Marañón, I., Ares, R., Ibáñez, F., Marzo, F. and Villarán, M. (2010). Microencapsulation of a probiotic and prebiotic in alginate-chitosan capsules improves survival in simulated gastro-intestinal conditions. International Journal of Food Microbiology 142 (1-2), 185-189.
Chaudhary, A. (2019). Probiotic fruit and vegetable juice: Approach towards a healthy gut. International Journal of Current Microbiology and Applied Sciences 8(6), 1265-1279.

Chew, S. C., Tan, C. H., Pui, L. P., Chong, P. N., Gunasekaran, B. and Nyam, K. L. (2019). Encapsulation technologies: A tool for functional foods development. International Journal of Innovative Technology and Exploring Engineering 8(5S), 154160.

Chew, S. C., Tan, C. P., Long, K. and Nyam, K. L. (2015). In-vitro evaluation of kenaf seed oil in chitosan coated-high methoxyl pectin-alginate microcapsules. Industrial Crops and Products 76(15), 230-236.

Chia, P., Tan, L., Huang, Y. C., Chan, C. E. and Wong, W. S. (2015). Hydrogel microbeads from sugar cane bagasse and palm kernel cake, and the viability of encapsulated Lactobacillus acidophilus. e-Polymers 15(6), 411-418.

Cook, M., Tzortzis, G., Charalampopoulos, D. and Khutoryanskiy, V. (2012). Microencapsulation of probiotics for gastrointestinal delivery. Journal of Controlled Release 162(1), 56-67.

Cremonini, F., Di Caro, S., Nista, E., Bartolozzi, F., Capelli, G., Gasbarrini, G. and Gasbarrini, A. (2002). Meta-analysis: The effect of probiotic administration on antibiotic-associated diarrhoea. Alimentary Pharmacology and Therapeutics 16(8), 1461-1467.

de Prisco, A., Maresca, D., Ongeng, D. and Mauriello, G. (2015). Microencapsulation by vibrating technology of the probiotic strain Lactobacillus reuteri DSM 17938 to enhance its survival in foods and in gastrointestinal environment. LWT - Food Science and Technology 61(2), 452-462.

de Vries, M. C., Vaughan, E. E., Kleerebezem, M. and de Vos, W. M. (2006). Lactobacillus plantarumsurvival, functional and potential probiotic properties in the human intestinal tract. International Dairy Journal 16(9), 1018-1028.

Ding, W. and Shah, N. (2008). Survival of free and microencapsulated probiotic bacteria in orange and apple juices. International Food Research Journal 12(2), 219-232.

Etchepare, M., Barin, J., Cichoski, A., Jacob-Lopes, E., Wagner, R., Fries, L. and Menezes, C. (2015). Microencapsulation of probiotics using sodium alginate. Ciencia. Rural 45(7), 1319- 1326.

Haghshenas, B., Abdullah, N., Yousef, N. and Radiah, D. (2015). Microencapsulation of probiotics bacteria Lactobacillus plantarum $15 \mathrm{HN}$ using alginate-psylliumfenugreek polymeric blends. Journal of Applied Microbiology 118(4), 1048-1057.

Hamon, E., Horvatovich, P., Izquierdo, E. , Bringel, F., Marchioni, E., Aoudé-Werner, D. and Ennahar, S. (2011). Comparative proteomic analysis of Lactobacillus plantarum for the identification of key proteins in bile tolerance. BMC Microbiology 11(1), 63.

Hansen, L., Allan-Wojtas, P., Jin, Y. and Paulson, A. (2002). Survival of Ca-alginate microencapsulated 
Bifidobacterium spp. in milk and simulated gastrointestinal conditions. Food Microbiology 19, 3545.

Hess, T., Jones, C., Hemphill, C. and Goodwin, K. (2014). The effect of temperature on diffusion rate through a semi-permeable membrane. Journal of Introductory Biology Investigations 1(2), 1-10.

Homayouni, A., Azizi, A., Ehsani, M., Yarmand, M. and Razavi, S. (2008). Effect of microencapsulation and resistant starch on the probiotic survival and sensory properties of synbiotic ice cream. Food Chemistry 111(1), 50-55.

Imran, M., Ferheen, S., Khalid, B. M., Sikander, F., Yaqeen, S. and Yaqeen, Z. (2017). An overview on fruit mango (Mangifera indica) life. International Journal of Biology, Pharmacy and Allied Sciences 6(7), 1434-1443.

Kechagia, M., Basoulis, D., Konstantopoulou, S., Dimitriadi, D., Gyftopoulou, K., Skarmoutsou, N. and Fakiri, E. M. (2013). Health benefits of probiotics: A review. International Scholarly Research Notices (ISRN) Nutrition 2013, Article ID 481651.

Mansouripour, S., Esfandiari, Z. and Nateghi, L. (2013). The effect of heat process on the survival and increased viability of probiotic by microencapsulation: A review. Annals of Biological Research 4(4), 83-87.

Matejčeková, Z., Spodniakova, S., Dujmić, E., Liptakova, D. and Valík, L'. (2019). Modelling growth of Lactobacillus plantarum as a function of temperature: Effects of media. Journal of Food and Nutrition Research 58(2), 125-134.

Moghtader, F., Eğri, S. and Piskin, E. (2017). Phages in modified alginate beads. Artificial Cells, Nanomedicine, and Biotechnology 45(2), 357-363.

Mortazavian, A., Razavi, S. H., Ehsani, M. R. and Sohrabvandi, S. (2007). Principles and methods of microencapsulation of probiotic microorganisms. Iranian Journal of Biotechnology 5(1), 1-18.

Mustafa, S., Chua, L., El-Enshasy, H., Majid, F. and Malek, R. (2016). A review on fruit juice probiotication: Pomegranate. Current Nutrition and Food Science 12(1), 4-11.

Nag, A. (2011). Development of a microencapsulation technique for probiotic Lactobacillus casei 431 using a protein-polysaccharide complex. M.Sc. Thesis. Massey University, New Zealand.

Nagpal, R., Kumar, A. and Kumar, M. (2012). Fortification and fermentation of fruit juices with probiotic Lactobacilli. Annual Microbiology 62(4), 1573-1578.

Naruszewicz, M., Johanson, M., Zapolska-Downar, D. and Bukowska, H. (2002). Effect of Lactobacillus plantarum $299 \mathrm{v}$ on cardiovascular disease risk factors in smokers. The American Journal of Clinical Nutrition 76(6), 1249-1255.

Nazzaro, F., Orlando, P., Fratianni, F. and Coppola, R. (2012). Microencapsulation in food science and biotechnology. Current Opinion in Biotechnology 23(2), 182-186.
Ng, S. L., Lai, K. W., Nyam, K. L. and Pui, L. P. (2019). Microencapsulation of Lactobacillus plantarum 299v incorporated with oligofructose in chitosan coatedalginate beads and its storage in ambarella juice. Malaysian Journal of Microbiology 15(5), 408-418.

Nualkaekul, S., Cook, M. T., Khutoryanskiy, V. V. and Charalampopoulos, D. (2013). Influence of encapsulation and coating materials on the survival of Lactobacillus plantarum and Bifidobacterium longum in fruit juices. Food Research International 53(1), 304311.

Nualkaekul, S., Lenton, D., Cook, M., Khutoryanskiy, V. and Charalampopoulos, D. (2012). Chitosan coated alginate microbeads for the survival of microencapsulated Lactobacillus plantarum in pomegranate juice. Carbohydrate Polymers 90(3), 1281-1287.

Ötles, S. and Ozgoz, S. (2014). Health effects of dietary fiber. Acta Scientiarum Polonorum Technologia Alimentaria 13(2), 191-202.

Ozcan, T., Yilmaz-Ersan, L., Akpinar-Bayizit, A., Delikanli, B. and Barat, A. (2015). Survival of Lactobacillus spp. in fruit based fermented dairy beverages. International Journal of Food Engineering 1(1), 44-49.

Pereiraa, A., Maciela, T. and Rodriguesa, S. (2011). Probiotic cashew apple juice. International Congress on Engineering and Food 1-6.

Perricone, M., Bevilacqua, A., Altieri, C., Sinigaglia, M. and Corbo, M. (2015). Challenges for the production of probiotic fruit juices. Beverages 1(2), 95-103.

Phoem, A. N., Chanthachum, S. and Voravuthikunchai, S. P. (2015). Applications of microencapsulated Bifidobacterium longum with Eleutherine Americana in fresh milk tofu and pineapple juice. Nutrients 7, 2469-2484.

Pimentel-González, D. J., Campos-Montiel, R. G., Lobato-Calleros, C., Pedroza,-Islas, R. and VernonCarter, E. J. (2009). Encapsulation of Lactobacillus rhamnosus in double emulsions formulated with sweet whey as emulsifier and survival in simulated gastrointestinal conditions. Food Research International 42(2), 292-297.

Sabnis, S. and Malavkar, N. (2016). Development of symbiotic double microencapsulation technique for efficient delivery of probiotics. International Journal of Current Microbiology and Applied Sciences 5(4), 306314.

Sahadeva, R. P. K., Leong, S. F., Chua, K. H., Tan, C. H., Chan, H. Y., Tong, E. V., Wong, S. Y. W. and Chan, H. K. (2011). Survival of commercial probiotics strains to $\mathrm{pH}$ and bile. International Food Research Journal 18(4), 1515-1522.

Sathyabama, S., Ranjith M. K., Bruntha-devi, P., Vijayabharathi, R. and Brindha, V. P. (2014). Coencapsulation of probiotics with prebiotics on alginate matrix and its effect on viability in simulated gastric environment. LWT-Food Science and Technology 57(1), 419-425. 
Savedboworn, W., Niyomrat, S., Naknovn, J. and Phattayakorn, K. (2017). Impact of inulin on viability and storage stability of probiotic Lactobacillus plantarum TISTR 2075 in fermented rice extract. Agriculture and Natural Resources 51(6), 463- 469.

Shah, R., Dave, N. and Roghelia, V. (2016). Development and analysis of probiotic and synbiotic fruit juice. Indian Journal of Technical Education (IJTE) 2016, 90-96.

Sheehan, V., Ross, P. and Fitzgerald, G. (2007). Assessing the acid tolerance and the technological robustness of probiotic cultures for fortification in fruit juices. Innovative Food Science and Emerging Technologies 8(2), 279-284.

Shi, L., Li, Z., Zhang, Z., Zhang, T., Yu, W., Zhou, M. and Tang, Z. (2013). Encapsulation of Lactobacillus bulgaricus in carrageenan-locust bean gum coated milk microspheres with double layer structure. LWT Food Science and Technology 54(1), 147-151.

Shinde, T., Sun-Waterhouse, D. and Brooks, J. (2013). Co-extrusion encapsulation of probiotic Lactobacillus acidophilus alone or together with apple skin polyphenols: An aqueous and value-added delivery system using alginate. Food Bioprocess Technology 7(6), 1581-1596.

Siang, S. C., Wai, L. K., Lin, N. K. and Phing, P. L. (2019). Effect of added prebiotic (isomaltooligosacchride) and coating of beads on the survival of microencapsulated Lactobacillus rhamnosus GG. Food Science and Technology 39(Suppl. 2), 601-609.

Solheim, M., Aakra, A., Vebo, H., Snipen, L. and Nes, I. (2007). Transcriptional responses of Enterococcus faecalis V583 to bovine bile and sodium dodecyl sulfate. Applied and Environmental Microbiology 73(18), 5767-5774.

Song, M., Yun, B., Moon, J., Park, D., Lim, K. and Oh, S. (2015). Characterization of selected Lactobacillus strains for use as probiotics. Korean Journal for Food Science of Animal Resources 35(4), 551-556.

Su, R., Zhu, X. L., Fan, D. D., Mi, Y., Yang, C. Y. and Jia, X. (2011). Encapsulation of probiotic Bifidobacterium longum BIOMA 5920 with alginatehuman-like collagen and evaluation of survival in simulated gastrointestinal conditions. International Journal of Biological Macromolecules 49(5), 979-984.

Teanpaisan, R., Chooruk, A. and Kampoo, T. (2015). Survival of free and microencapsulated humanderived oral probiotic Lactobacillus paracasei SD1 in orange and aloe vera juices. Songklanakarin Journal of Science and Technology 37(3), 265-270.

Tootoonchi, P., Hesari, J., Moradi, M. and Mehrnoosh, F. (2015). Survival of encapsulated Latobacillus acidophilus LA5, and Lactobacillus casei 431 encapsulated in orange juice stored in refrigerator temperature. International Journal of Biology, Pharmacy and Allied Sciences 4(8), 268-276.

Yee, W. L., Yee, C. L., Lin, N. K. and Phing, P. L. (2019). Microencapsulation of Lactobacillus acidophilus NCFM incorporated with mannitol and its storage stability in mulberry leaf tea. Ciência $e$ Agrotecnologia 43, 1-11.

Zanjani, M., Tarzi, B., Sharifan, A. and Mohammadi, N. (2014). Microencapsulation of probiotics by calcium alginate-gelatinized starch with chitosan coating and evaluation of survival in simulated human gastrointestinal condition. Iranian Journal of Pharmaceutical Research 13(3), 843-852.

Zneimer, S. M. (2017). Cytogenetic Laboratory Management. John Wiley \& Sons, Canada. pp. 209251. 